EGU2020-19548, updated on 17 Mar 2020

https://doi.org/10.5194/egusphere-egu2020-19548

EGU General Assembly 2020

(c) Author(s) 2020. This work is distributed under

the Creative Commons Attribution 4.0 License.

\title{
Does organic carbon hold micrometeoroids together?
}

David L. Bones ${ }^{1}$, Juan Diego Carrillo-Sánchez ${ }^{1}$, Alexander D. James ${ }^{1,2}$, Simon D. Connell ${ }^{3}$, John M. C. Plane ${ }^{1}$, and Graham W. Mann ${ }^{2}$

'University of Leeds, School of Chemistry, Leeds, United Kingdom of Great Britain and Northern Ireland

(d.l.bones@leeds.ac.uk)

${ }^{2}$ University of Leeds, School of Earth and Environment, Leeds, United Kingdom of Great Britain and Northern Ireland

${ }^{3}$ University of Leeds, School of Physics and Astronomy, Leeds, United Kingdom of Great Britain and Northern Ireland

The cosmic dust input into the Earth's atmosphere has been estimated at 28 tonnes per day. However, the models behind this estimate do not include fragmentation. If the particles fragment significantly, the input rate of dust would be considerably higher. Millimetre sized meteoroids have been observed to fragment. If this is true for the majority of the cosmic dust particles that enter the Earth's atmosphere (size range 10 micron to $1 \mathrm{~mm}$ ), it would make a difference to the rates of ablation of these particles and our understanding of the meteoric inputs into the Earth's mesosphere. Fragmentation would result in a broader size distribution and a greater number of 0.2 - 1.0 micron-sized particles sedimenting into the stratosphere.

The Meteoric Ablation Simulator (MASI) is a chamber for investigating the ablation of volatile species from meteoroid proxies. Here, we run it at relatively low temperatures to investigate the pyrolysis of hydrocarbon compounds. It has been proposed that organic carbon compounds act as a glue to hold the grains within micrometeoroids together. The carbon compounds are thought to be tarry, refractory kerogen compounds similar to those found in terrestrial oil shale. At moderate temperatures, these compounds pyrolyse into species such as butane and pentane.

The MASI employs a heated surface, the temperature of which can be varied from 300 to $1200 \mathrm{~K}$. Once the surface is up to temperature, particles are dropped onto it. The ablating carboncontaining compounds are detected by mass spectrometry. The majority of the ablated carbon combusts to $\mathrm{CO}_{2}$. Measuring the rate of $\mathrm{CO}_{2}$ production as the particles are exposed to specific temperatures enables the temperature-dependent rate of pyrolysis of the carbon compounds to be measured.

To measure the effect of the removal of the carbon compounds on the strength of the particle, particles are subjected to yield stress tests in an atomic force microscope (AFM). Particles that have been flash heated, breaking bonds in the hydrocarbon glue, are expected to be more fragile.

Powdered meteorite samples (2\% organic carbon) lose carbon over a broader range of temperatures than powdered oil shale (15\% organic carbon). The effective activation energies measured for this pyrolysis are low - about 90 and $60 \mathrm{~kJ} \mathrm{~mol}^{-1}$ for the oil shale and CM2 meteorite, respectively. This is likely a combination of 1 ) particles not reaching the surface temperature due 
to evaporative cooling and 2) the complexity of the reactions occurring in the carbonaceous particles as they heat. Analysis of TGA traces for oil shale samples give a higher effective activation energy of $191 \mathrm{~kJ} \mathrm{~mol}^{-1}$. This value agrees with other TGA analyses of oil shale. In both cases, the biggest loss of carbon happens at around $700-800 \mathrm{~K}$. AFM yield stress tests show evidence of fracturing, but so far only at pressures too high to be relevant for fragmentation in the atmosphere. 